\title{
RHETORIC AND TECHNICAL IRITIMG--A HEALTHY LIAISON
}

\author{
Michael P. Jordan
}

The planned joint session between the CATTW and the CSHR (Canadian Society for the History of Rhetoric) at the Learneds in Hamilton next May provides a clear opportunity to re-assess each discipline in light of the other. There are striking similarities between the two specialities, and many of the underlying educational aims are common. There are also differences, however; and recognition of our shared and different aims and practices should prove mutually advantageous. This essay explores the possibilities.

Major characteristics of the best rhetorical tradition have been defined (Lunsford, 1986) as:

(a) a strong interdisciplinary interest,

(b) the claim to be a central concern of higher education,

(c) an effective combination of theory and practice,

(d) instruction and practice in writing, reading and speaking, and

(e) an interactive teaching approach with strong student participation.

Technical writing (especially as broadly defined by the CATTW) is clearly inter-disciplinary. It encompasses not only the natural sciences and technology, but also medical and agricultural sciences, business and administration, and in fact any form of functional communication. The aims of many writing centres are to provide a focus for communication studies and to teach comnunication skills to students of all interests. In addition, technical writing teachers are frequently sought out by colleagues for advice on the techniques and traditions of effective communication. While few writing instructors and departments have yet achieved the central position in the curriculum deservedly enjoyed by the eighteenth-century rhetoricians, many feel their work deserves such recognition and that they could contribute significantly to the overall educational aims of their institution. The aims of technical writing are considerably broader than Quintilian's "good man skilled in speaking" and Cicero's "learned orator," but the aims of both specialities are quite similar, are highly compatible, and are clearly central to true education.

Perhaps the most striking similarity between technical writing and post-Renaissance rhetorical instruction is the reliance on a blend of theory and practice. Simply knowing how to speak or write is not good enough--the student needs constant guided practice to hone a variety of communication skills, to build confidence in an ability to control any communication situation, and to develop an ability to use the theoretical background as the basis for self-improvement and peer judgement. Although technical writing has, almost by definition, been primarily concerned with writing, both reading and speaking are often 
found as important elements of communication courses and programmes, and a fourth medium--drawings--is also of prime concern.

The interactive teaching ethos of eighteenth- and early nineteenthcentury rhetorical teaching (practised until quite recently by select English universities) is the envy of any teacher. A small class of keenly-participating students learning and exploring a subject with their teacher can now only be justified economically for graduate work or special courses. Nevertheless both technical writing instructors and rhetoricians appear to share the ideal, and do whatever they can to emulate it under current conditions. The will is there, but not always the means.

A sixth similarity is an openness to ideas and scholarship from other branches of learning. Rhetoric has had a long (though not always harmonious) relationship with philosophy, and is open to work in psychology and linguistics. Similarly technical writing has leaned heavily on inter-personal psychology and is making use of work in discourse analysis and other branches of applied language study. The present liaison between the two groups is a further indication of this openness to other views and approaches.

The differences are at least as interesting as the similarities.

Although eighteenth-century rhetoricians succeeded in synthesizing the knowledge of the time within the communicative arts, rhetoric failed to meet the communication needs of medicine, engineering, science, business and advertising. The main concern, oratory concerning public issues, is still tremendously important, but such overconcentration is unlikely to be perceived as a matter of central educational concern. In contrast technical writing is striving to recognize and meet the communication needs of all students for all purposes--and this at least has the potential for wider recognition as a topic of central importance.

The prime medium of concern for ancient rhetoric was of course speech, with emphasis on formal presentation, public discussion and disputation. Rhetoricians later integrated the skills of writing and reading to provide a broad-based educational background for their students. The emphasis in technical writing (as opposed to speaking and reading) has been slow to change for practical and theoretical reasons, but the effective use of graphs, charts, photographs and various types of illustrations has long been seen as an important element of instruction.

Modern rhetoric embraces emotional as well as reasoned argument as a valid method of persuasion, and there can be no doubt there are suitable forums for it--jury trials and advertising, for example. For most technical writing, however, the argument needs to be reasoned rather than emotional, and this applies for almost all student communications even when analyzing emotional issues in literature, political 
science or psychology. For most teaching, technical writing teachers would probably accept Aristotle's (Rhetoric) plea for the use of bare facts, but would recognize the need for an understanding of readers" emotions and appeal to them when appropriate. This balanced view with preference on reason rather than emotion appears to coincide with Aristotle's view, but not with that of some later writers.

Rhetoricians, with a clearly documented tradition of broad education and scholarship, enjoy a much wider mandate than technical writing teachers, who have to meet the practical needs of their students. To meet these needs, instructors have, in the past, been recruited from science and technology, information science, professional writing, and classical studies as well as from literary studies. This has resulted in a practical and truly inter-disciplinary group of teachers, but the obvious advantages have been gained at the expense of scholarship. The rhetorician's plea for less reliance on prescriptive standards of usage has largely fallen on deaf ears, and technical writing has yet to build a body of theory which will earn for it the academic respect enjoyed by rhetoric.

\section{What can we learn from each other?}

Technical writing teachers can more openly teach the legitimacy of the communicator having personal aims which do not always have to be subordinated to the readers' needs. They can seek to understand the humanities basis for rhetorical study, and work towards true education of integrated communications skills. And they can shake loose from the complacency built on prescriptive rules, and thus help to build theory that will lead to scholarly acceptance of the principles being taught.

Rhetoricians can concentrate on research in rhetoric rather than its history. They can return to the practical matter of educating students to communicate, with more talk about issues and less talk about talk. And they can broaden their outlook to include the detailed study of composition, advertising and yes, even technical prose, and thus join communication scholars of all specialities in developing a greater understanding of all communication arts in all genres.

Aristotle. Rhetoric: The Complete Works of Aristotle, Vol. 2. (J. Barnes, ed.) Bollingen Series, Princeton University Press, 1984, pp. 1354a, 1404a.

Lunsford, A. "The Past--and Future--of Rhetorical Instruction" Proceedings of the Canadian Society for the History of Rhetoric W.S. Martin and C.M. Sutherland, eds.), 1984, p. 104.

Mike Jordan teaches rhetoric and technical writing at Queen's University. 